\title{
The use of simplified verbal autopsy in identifying causes of adult death in a predominantly rural population in Ethiopia Kidest Lulu ${ }^{1}$ and Yemane Berhane*2
}

Address: ${ }^{1}$ Department of Community Health, Jimma University, Jimma, Ethiopia and ${ }^{2}$ Department of Community Health, Faculty of Medicine, Addis Ababa University, P.o. Box 2077, Addis Ababa, Ethiopia

Email: Kidest Lulu - kidestlulu@yahoo.com; Yemane Berhane* - rhr.aau@ethionet.et

* Corresponding author

Published: 03 June 2005

BMC Public Health 2005, 5:58 doi:10.1 I86//47|-2458-5-58
Received: 15 September 2004

Accepted: 03 June 2005

This article is available from: http://www.biomedcentral.com/I47I-2458/5/58

(C) 2005 Lulu and Berhane; licensee BioMed Central Ltd.

This is an Open Access article distributed under the terms of the Creative Commons Attribution License (http://creativecommons.org/licenses/by/2.0), which permits unrestricted use, distribution, and reproduction in any medium, provided the original work is properly cited.

\begin{abstract}
Background: Information on adult mortality is essentially non-existent in Ethiopia particularly from rural areas where access to health services is limited and most deaths occur at home. This study was conducted with the aim of identifying causes of adult death in a rural population of Ethiopia using a simplified verbal autopsy instrument.
\end{abstract}

Methods: All deaths in the age-group 15-49 years during the period of 1995-99 were taken from computerized demographic surveillance database maintained by the Butajira Rural Health Program. Data on the causes of death were collected from close relatives of the deceased persons by lay interviewers. Causes of death were diagnosed using "expert algorithm" programmed onto a computer.

Results: The major causes of death were acute febrile illnesses (25.2\%), liver diseases (II.3\%), diarrheal diseases (II.I\%), tuberculosis $(9.7 \%)$ and HIVIAIDS (7.4\%). Overall communicable diseases accounted for $60.8 \%$ of the deaths. The high levels of mortality from communicable diseases reflect the poor socioeconomic development of the country, and the general poor coverage of health and education services in rural Ethiopia. The tools used in this study can easily be added-on to the numerous health surveys conducted in the country.

Conclusion: The simplified approach to verbal autopsy diagnosis can produce useful data that can effectively guide priority health interventions in rural areas where routine information system is either very weak or non-existent.

\section{Background}

Mortality statistics have several advantages when compared to other sources of health information such as morbidity data as death is a unique event that is remembered for long time and because of its finality it is clearly defined. Thus, statistics on cause of death are reliable and useful in guiding priority interventions in public health [1].
In developing countries, where most deaths are neither attended by doctors nor medically certified, information on causes of death is usually incomplete and of poor quality [2]. To alleviate the problem in resource poor countries an indirect method called verbal autopsy (VA), which makes use of lay reporters, has been adopted to identify causes of death. It uses information on the circumstances leading to death, symptoms and signs during the terminal 
illness, obtained from the family of the deceased, to assign cause of death. VA data are generated through retrospective questioning in surveys or in demographic surveillance systems [3-6].

The VA technique is based on the assumption that most causes of death have distinct symptom complexes that can be recognized, remembered and reported by lay respondents. It assumes that it is possible to classify deaths based on the reported information into useful categories of causes of death. The validity of VA is influenced by the type of illness leading to death, characteristics of the deceased person, and other factors related to the classification of causes of death, as well as the design and content of the questionnaire and field procedures $[5,7,8]$.

Factors that affect the validity of a VA include the approach to mortality classification, the design of the questionnaire, the methods of deriving a diagnosis, and the number and combinations of categories of causes of death assigned. The choice of categories of causes of death determines the complexity of diagnostic algorithms. A classification approach using fewer categories will group causes of death with closely related symptom complexes together and hence tends to increase the validity of the VA but provides less detailed information. The other advantage in broadly classifying mortality is that the classification can be used in a wide range of settings with minor modifications [5].

The type of questionnaire also influences the validity of the VA outcome. An open format VA questionnaire would require skilled and possibly medically trained interviewers, and would also have a higher inter-interviewer variability. A checklist with filters on the other hand would not need medically trained interviewers, and would be more efficient for data collection. But, a false negative answer to a filter question will result in omitting one whole disease category and hence decrease the sensitivity of the VA. A checklist without filters would not require a medically trained person and would reduce interviewer bias, but it may not capture all details of the symptoms leading to death and may increase the number of falsely reported symptoms [5].

Different validation studies for the VA method have been done for deaths in children [9-12], and adults $[6,13]$ suggesting that the VA method is an important tool for diagnosing causes of death, especially in developing countries. Studies in Tanzania [14] and in Ethiopia [15] have shown the robustness of VA method in identifying cause of death using lay interviewers.

Trends in cause-specific mortality over time, differentials of mortality between different population groups, or eval- uation of the effect of interventions can be studied from data using the VA method. Additionally, they can be used to establish the relative public health importance of different causes of death in the populations in order to identify priorities and appropriate interventions $[5,16]$

Ethiopia is a country where low standards of living, poor environmental conditions and under developed social services have caused serious impact on the health status of the population $[17,18]$. Although adults are the pillar of the society as economically productive, biologically reproductive, and responsible for the support of children and elderly dependents their health needs receive little attention in developing countries [19]. Information on adult health conditions is essentially non-existent in most developing countries as the routine system does not cover large segment of the population, especially those living in the rural areas $[2,20,21]$. In Ethiopia, due to the absence of vital event registration system and inaccessibility of health facilities most deaths occur at home and pass undocumented. This study was done with the objective of identifying the causes of death in a predominantly rural population where almost all deaths are occurring at home. The paper tries to demonstrate a possibility of using a relatively simple and inexpensive verbal autopsy method for obtaining valuable data in improving health services to the rural underserved populations.

\section{Methods}

The study district, Meskan and Mareko, is located in the central-south part of Ethiopia at an average altitude of 2,100 meters above sea level with a range of $1,750 \mathrm{~m}$ in the low lands to $3,400 \mathrm{~m}$ in the mountainous areas. The actual study sites were the nine rural and one urban study kebeles (Kebele is the smallest administrative unit in Ethiopia often having an average of 500 households, the size varies significantly from district to district) that are under continuous demographic surveillance by the Butajira Rural Health Program (BRHP). These sites were randomly selected using the probability proportionate to size technique. The BRHP registers events such as birth, death, marriage, new household, out-migration, in-migration, and internal move. Information on the circumstances leading to death was not routinely collected by the surveillance system. Data on mortality as well as the above mentioned events were collected monthly, by trained villagebased enumerators, through household visits. The total population of the area was estimated to be 257,000 in 1999. Detailed description of the study area is given elsewhere [22].

All adult deaths in the age group 15 to 49 year that were registered by the BRHP from January 1995 to December 1999 were identified from the longitudinal surveillance database and considered for this study. The age-group 15- 
Table I: Algorithm used for the diagnoses of cause of death, in Meskan and Mareko district, Ethiopia. 2000.

\begin{tabular}{ll}
\hline Algorithm & Diagnosis \\
\hline Duration of illness $<30$ days + Accidents (intentional or unintentional) & Injuries \\
Female sex + (Pregnant or In labor or in the puerperal period) & Maternal causes \\
Duration of illness $>30$ days + Cough + Weight loss + (Bloody sputum or Fever or Ascites) + no diarrhea & Tuberculosis \\
Duration of illness $>30$ days + Cough + Diarrhea + Fever + Weight loss & AIDS \\
Duration of illness $>15$ days + (Edema of legs or Ascites) + Jaundice & Liver diseases \\
Duration of illness $<15$ days + Abdominal swelling + Repeated vomiting + No diarrhea & Acute abdomen \\
Duration of illness $>30$ days + cough + Dyspnea + Wheezing + No bloody sputum & Chronic obstructive lung diseases \\
Duration of illness $<30$ days + Diarrhea + No cough & Diarrheal diseases \\
Duration of illness $<15$ days + Fever + Headache & Acute febrile illness \\
Duration of illness $<15$ days + Fever + Headache + Neck stiffness & Meningitis \\
Duration of illness $<30$ days + Cough + Fever + (Dyspnea or Chest pain) & Pneumonia \\
Duration of illness $<30$ days + Dyspnea + Palpitation + (Edema of legs or Ascites) & Cardio Vascular diseases \\
\hline
\end{tabular}

49 was selected for this study in order to identify the causes of premature adult death, since life expectancy at birth in Ethiopia is 53 years for females and 50.9 years for males $[17,23]$.

Data were collected using a simplified verbal autopsy questionnaire administered to relatives of the deceased. The questionnaire for this study was developed based on the WHO questionnaire for identifying cause of death in children and modified to address adult signs and symptoms of diseases [8]. It was initially prepared in English and then translated to Amharic (the national language). The first part of the questionnaire has questions on the socio-demographic characteristics of the subjects such as area of residence, age, sex, marital status, education, economic status, health service usage; and their personal habits such as smoking and alcohol drinking. The second part has questions on circumstances surrounding mortality such as signs and symptoms of illness, duration of illness, health care seeking, medications used, and admission to a health facility. The interview on average took about 20 minutes. The VA questionnaire used in this study is short and simplified. That was done for the following reasons: to develop a less complicated questionnaire that can be used by lay interviewers with minimal training; to get adequate response to all questions from rural and illiterate people; to make the questionnaire suitable for annexing into routine surveillance systems in the future; to facilitate the development of an uncomplicated algorithm for identifying broad categories of cause of death; and to obtain fairly complete information about each death. Data collectors and supervisors were recruited from the study area. The data collectors were all high school graduates with good experience in a similar type of fieldwork. Data collectors went house to house to collect information about the deceased person identified from the study base. In the event respondents were not available on first visit, repeated visits were arranged on at least two occasions.

Data entry and analysis were done using Epi Info version 6.04 statistical package. Causes of death were analyzed using an expert algorithm programmed into a computer. The algorithm does not include cancer as one category mainly because health records did not show cancer as major causes of either hospital admission or hospital death for adults in Ethiopia $[17,23]$. The second reason is that because of the varied manifestations for different types of cancers, it would be difficult to accommodate deaths due to cancer into the simple questionnaire and algorithm used in this study. The algorithms used are shown in Table 1.

\section{Results}

A total of 819 adult (15-49 years) deaths were identified from the BRHP computer database for the period 19951999. In the field appropriate respondents (family members and close relatives) were identified for 515 (63\%) of the deceased persons. The reasons for not identifying the rest include out-migration of the entire family of the deceased person, unavailability of relatives on repeated visits, wrong recorded information about the deceased, and double recording. The highest proportion of the missed cases (59.7\%) was for those who died in the initial one and half years of the study. From those who died in the last one and half years of the study only $19.4 \%$ of the cases were missed. Communicable diseases accounted for $60.8 \%$ of the deaths, non-communicable for $24.1 \%$, maternal causes $7 \%$, injuries $1.7 \%$, and undetermined causes consisted of $6.4 \%$. The highest number of deaths was due to acute febrile illnesses (AFI) comprising 25.2\% of all causes. AFI, diarrheal diseases, tuberculosis, AIDS, and liver diseases together accounted for $64.7 \%$ of the deaths (Table 1). AFI was the cause for $28 \%$ and $25.5 \%$ of 
Table 2: Possible verbal autopsy based causes of death by area of residence in Meskan and Mareko district, Ethiopia. $1995-1999$.

\begin{tabular}{|c|c|c|c|c|}
\hline Possible cause & $\begin{array}{l}\text { Urban } \\
\text { No. (\%) }\end{array}$ & $\begin{array}{l}\text { Rural highland } \\
\text { No. (\%) }\end{array}$ & $\begin{array}{l}\text { Rural lowland } \\
\text { No. (\%) }\end{array}$ & $\begin{array}{l}\text { Total } \\
\text { No. (\%) }\end{array}$ \\
\hline I. Communicable Diseases & $37(52.1)$ & $150(63.6)$ & $126(60.6)$ & $313(60.8)$ \\
\hline Acute Febrile illnesses & II (I5.5) & $66(28.0)$ & $53(25.5)$ & $130(25.2)$ \\
\hline Diarrheal diseases & $5(7.0)$ & $25(10.6)$ & $27(13.0)$ & $57(11.1)$ \\
\hline All forms of tuberculosis & $6(8.5)$ & $23(9.7)$ & $21(10.1)$ & $50(9.7)$ \\
\hline HIV/ AIDS & $8(11.3)$ & $20(8.5)$ & $10(4.8)$ & $38(7.4)$ \\
\hline Pneumonia & $4(5.6)$ & $14(5.9)$ & $10(4.8)$ & $28(5.4)$ \\
\hline Meningitis & $3(4.2)$ & $2(0.8)$ & $5(2.4)$ & $10(1.9)$ \\
\hline II. Non-communicable Diseases & $20(28.2)$ & $56(23.7)$ & $48(23.1)$ & $124(25.4)$ \\
\hline Liver diseases & $8(11.3)$ & $26(11.1)$ & $24(11.5)$ & $58(I I .3)$ \\
\hline Cardio-vascular diseases & $6(8.5)$ & $13(5.5)$ & $13(6.3)$ & $32(6.2)$ \\
\hline $\begin{array}{l}\text { Chronic obstructive lung } \\
\text { diseases }\end{array}$ & $4(5.6)$ & $14(5.9)$ & $9(4.3)$ & $27(5.2)$ \\
\hline Acute abdomen conditions & $2(2.8)$ & $3(1.3)$ & $2(0.9)$ & $7(1.4)$ \\
\hline III. Maternal causes & $3(4.2)$ & $19(8.1)$ & $14(6.7)$ & $36(7.0)$ \\
\hline IV. Injuries & $2(2.8)$ & $6(2.5)$ & $\mathrm{I}(0.5)$ & $9(1.7)$ \\
\hline Undetermined & $9(12.7)$ & $5(2.1)$ & $19(9.1)$ & $33(6.4)$ \\
\hline Total & $71(100)$ & $236(100)$ & $208(100)$ & $515(100.0)$ \\
\hline
\end{tabular}

the deaths in the rural highland, and lowland areas respectively, while it accounted to only $15.5 \%$ of the urban deaths. Diarrheal diseases accounted for $7 \%$ of the deaths in the urban area, $10.6 \%$ in the rural highland and $13 \%$ in the rural lowland. However, HIV/AIDS in the urban area accounted for $11.3 \%$ in contrast to $8.5 \%$ and $4.8 \%$ in the rural highland and lowland (Table 2).

In general, deaths from communicable diseases was greater in males $(62.8 \%)$ than in females $(58.7 \%)$; while deaths from non-communicable diseases was greater in females $(35.4 \%)$ than in males $(26.8 \%)$. Maternal mortality accounted for $7 \%$ of all deaths, and $14.2 \%$ of the female deaths (Table 3). Of the 36 women identified to have died from maternal causes; 17 (47.2\%) had fever, 10 $(27.8 \%)$ had prolonged labor, and $4(11.1 \%)$ had hemorrhage.

Since a large proportion of the deaths that occurred in the first one and half year of the study were missed, analysis of cause of death was also made for the deaths excluding the initial one and half year. There were a total of 422 cases found in this category. Communicable diseases accounted for $59.2 \%$ of the deaths, non-communicable $25.4 \%$, maternal causes $6.9 \%$, injuries $0.9 \%$ and undetermined causes were $7.6 \%$ (Table 4 ).

\section{Discussion}

This study has attempted to identify the causes of death at a district level based on a simplified verbal autopsy procedure. Although information of this type is recognized to be very important for health planning and decision making it is largely nonexistent in developing countries, especially in rural settings. In the study area the major causes of death were acute febrile illnesses, liver diseases, diarrheal diseases, tuberculosis and HIV/AIDS. Maternity related causes accounted for $14.2 \%$ of the total female deaths. The questionnaire was made short and easily understandable to enhance its application on illiterate rural respondents by lay interviewers. The simplification has narrowed the possibilities of making very specific diagnoses that are claimed to be achieved using a more elaborate questionnaire. On the other hand, it would have been impossible to obtain complete data using elaborated questionnaire administered by lay interviewers, especially for the deaths that occurred long ago. In rural areas it is very difficult, if not impossible, to find interviewers with fairly high level of education that can administer and record an elaborate open ended questionnaire. In this study no major problem was detected on the completed questionnaires that can be attributed to the data collector's incompetence.

Information was collected as far back as five years. We observed that the loss of the beloved is unforgettable in 
Table 3: Possible verbal autopsy causes of death by sex in Meskan and Mareko district, Ethiopia. $1995-1999$.

\begin{tabular}{|c|c|c|c|}
\hline Possible cause & $\begin{array}{l}\text { Females } \\
\text { Number (\%) }\end{array}$ & $\begin{array}{l}\text { Males } \\
\text { Number (\%) }\end{array}$ & $\begin{array}{l}\text { Total } \\
\text { Number (\%) }\end{array}$ \\
\hline I. Communicable Diseases & 149 (58.7) & $164(62.8)$ & $313(60.8)$ \\
\hline Acute Febrile illnesses & $63(24.8)$ & $67(25.7)$ & $130(25.2)$ \\
\hline Diarrheal diseases & $28(11.0)$ & $29(11.1)$ & $57(I I . I)$ \\
\hline All forms of tuberculosis & $21(8.3)$ & $29(11.1)$ & $50(9.7)$ \\
\hline HIV/ AIDS & $19(7.5)$ & $19(7.3)$ & $38(7.4)$ \\
\hline Pneumonia & $17(6.7)$ & II (4.2) & $28(5.4)$ \\
\hline Meningitis & I $(0.4)$ & $9(3.4)$ & $10(1.9)$ \\
\hline II. Non-communicable Diseases & $54(21.2)$ & $78(26.8)$ & $124(25.4)$ \\
\hline Liver diseases & $26(10.2)$ & $32(12.3)$ & $58(\mathrm{II} .3)$ \\
\hline Cardio-vascular diseases & $14(5.5)$ & $18(6.9)$ & $32(6.2)$ \\
\hline $\begin{array}{l}\text { Chronic obstructive lung } \\
\text { diseases }\end{array}$ & $10(3.9)$ & $17(6.5)$ & $27(5.2)$ \\
\hline Acute abdomen conditions & $4(1.6)$ & $3(1.1)$ & $7(1.4)$ \\
\hline III. Maternal causes & $36(14.2)$ & --- & $36(7.0)$ \\
\hline IV. Injuries & $3(1.2)$ & $6(2.3)$ & $9(1.7)$ \\
\hline Undetermined & $12(4.7)$ & $21(8.1)$ & $33(6.4)$ \\
\hline Total & $254(100.0)$ & $26 I(100.0)$ & $515(100.0)$ \\
\hline
\end{tabular}

Table 4: Possible verbal autopsy based causes of death for the last three and half years of the recall period as compared to the total five years in Meskan and Mareko district, Ethiopia. 1995-1999.

\begin{tabular}{|c|c|c|}
\hline \multirow[t]{3}{*}{ Possible cause } & \multicolumn{2}{|c|}{ Year of death } \\
\hline & $09 / 01 / 96-12 / 31 / 99$ & $01 / 01 / 95-12 / 31 / 99$ \\
\hline & Number (\%) & Number (\%) \\
\hline I. Communicable Diseases & $250(59.2)$ & $313(60.8)$ \\
\hline Acute Febrile illnesses & $102(24.2)$ & $130(25.2)$ \\
\hline Diarrheal diseases & $47(11.1)$ & $57(11.1)$ \\
\hline All forms of tuberculosis & $42(10.0)$ & $50(9.7)$ \\
\hline HIV/ AIDS & $30(7.1)$ & $38(7.4)$ \\
\hline Pneumonia & $22(5.2)$ & $28(5.4)$ \\
\hline Meningitis & $7(1.7)$ & $10(1.9)$ \\
\hline II. Non-communicable Diseases & $95(25.4)$ & $124(25.4)$ \\
\hline Liver diseases & $49(11.6)$ & $58(I 1.3)$ \\
\hline Cardio-vascular diseases & $29(6.9)$ & $32(6.2)$ \\
\hline Chronic obstructive lung diseases & $23(5.5)$ & $27(5.2)$ \\
\hline Acute abdomen conditions & $6(1.4)$ & $7(1.4)$ \\
\hline III. Maternal causes & $29(6.9)$ & $36(7.0)$ \\
\hline IV. Injuries & $4(0.9)$ & $9(1.7)$ \\
\hline Undetermined & $32(7.6)$ & $33(6.4)$ \\
\hline Total & $422(100.0)$ & $515(100.0)$ \\
\hline
\end{tabular}


the study community and reported without any reservation, especially for adults. The recall period however can affect the quality of detailed information collected for VA use. Baqui utilized a five year recall period for children in Bangladesh and reported that increase recall lapse has no clear adverse effect on data quality [24]. In addition, the questions on events surrounding mortality in this study are very simple and direct. For example, one of the questions was on duration of illness in general, not on duration of specific symptoms. The omission of very specific questions was helpful in minimizing the problem of recall. The major problem associated with the long time span was the unavailability of relatives of the deceased for interview, due to out migration or other reasons. There was a marked decline in the proportion of the missed cases from 1995 to 1999. The high number of missed cases for the deaths during "01/01/95"-"08/31/97" may have affected the results of this study and can be sighted as one of the limitations encountered. This indicates that VA information need to be gathered closer to the event, i.e. within a time span of not more than two years. The simplified algorithm used for diagnosis of cause of death classified illnesses into "broad" categories consisting of 12 causes of death. For example all acute febrile illnesses and all forms of tuberculosis were lumped into one category. Although this "broad" classification has the disadvantage of diagnosing only a limited variety of diseases and leaving out some diseases as undetermined, it makes easier the use of VA and the algorithm in many similar settings once validated. Other studies have demonstrated that simplicity of the questionnaire, the use of lay interviewers, lack of complexity in the algorithm used, and the broad categories of diseases increase the validity of a study and its reproducibility in other settings [6].

Although a validation study was not done on the "expert algorithm" used, the combinations of symptoms and duration of illness used for diagnosing injuries, maternal deaths, acute febrile illnesses, and meningitis are believed to be highly sensitive but not very specific. For example the algorithm of AFI has the combination of "duration of illness less than 15 days", "fever" and "headache". This combination can pick almost all deaths due to AFIs, but it increases the false positivist.

The algorithm used for tuberculosis, AIDS, liver diseases, and pneumonia are less sensitive but more specific than the previously stated diseases categories, because of the sign and symptom combinations used. A validation study for verbal autopsy in adults had shown that the cause specific mortality fraction obtained using "expert algorithms" was within $\pm 20 \%$ of the gold standard for malaria, meningitis, tuberculosis/AIDS, acute abdomen conditions, diarrheal diseases, direct maternal causes, chronic liver diseases and renal disorders [14].
The algorithm used for cardiovascular diseases and chronic obstructive pulmonary diseases may not have performed well because of the unstable nature of the diseases resulting in difficulty of sighting symptoms specific to them [7]. The "expert algorithm" used in this study may not have given the correct diagnosis for some of the diseases at the individual level. However, in the face of absence of information on causes of mortality in Ethiopia, the information generated at the population level using these combinations is very useful in identifying priority health problems that need urgent intervention in rural populations.

Causes of death diagnosed through the expert algorithm showed that one fourth of the deaths were due to acute febrile illnesses. The proportion was much higher in the rural areas than in the town. In contrast, HIV/AIDS accounted for a higher proportion in the town than the rural areas. A previous study in the same area has shown a similar pattern of disease occurrence [16].

We have tried to see if there is any inconsistency in the causes of death as a result of the greater number of missed cases in the first one and half year of the study period. The deaths during the later period of the study have very similar pattern when compared to the total five year deaths. For communicable diseases it was $60.8 \%$ vs. $59.2 \%$, for non-communicable $24.1 \%$ vs. $25.4 \%$ and for maternal causes $7 \%$ vs. $6.9 \%$. This consistency can be taken as an indicator of non-differential loss of cases over the specified period of time. This also indicate the robustness of the approach even when data are not complete, which is truly the case in most rural settings of developing countries.

This study has grossly indicated the magnitude of female deaths due to maternal causes, which is very difficult to come by as measuring maternal mortality ratio is very expensive [25-27], such information could be helpful to implement practical interventions locally. Considerations in the line of using the probabilistic approach to interpreting verbal autopsies described by Byass might help to further simplify the methodology and facilitate its application in large surveys [28]. However, it is important to note that the questionnaire in this study was tailored to yield maximum information from mostly illiterate and rural people as administered by lay interviewers. Hence its applicability might be limited to situations similar to the study area both in terms of availability of information and profile of health problems, which is dominated by communicable diseases.

\section{Conclusion}

In conclusion, this study provides evidence that interviewing deceased relatives using a simplified VA questionnaire 
and expert algorithm for diagnosis of causes of death can provide information on priority health problems in resource poor communities of developing countries. The importance of having local information for planning appropriate health interventions at district level is demonstrated in the same area [29]. We encourage more researches to further develop this simplified VA questionnaire and expert algorithm, and to do a validation study in order to enhance its applicability in larger scale health surveys.

\section{Competing interests}

The author(s) declare that they have no competing interests.

\section{Authors' contributions}

KL participated in the design of the study, field data collection, data analysis, and prepared the draft manuscript. YB participated in the design of the study, field data collection, and data analysis and revised the draft manuscript. Both authors read and approved the final manuscript.

\section{Acknowledgements}

Authors gratefully acknowledge the financial support from the Irish Embassy and Irish Aid, Addis Ababa, Ethiopia. Authors also acknowledge technical and material support obtained from the Department of Community Health, Faculty of Medicine, Addis Ababa University. Special thanks go to the Butajira Rural Health Program and its field staff.

\section{References}

I. Ruzicka LT, Lopez AD: The use of cause-of-death statistics for health situation assessment: national and international experiences. World Health Stat $Q$ 1990, 43(4):249-58.

2. Lopez AD: Causes of death: an assessment of global patterns of mortality around 1985. World Health Stat Q 1990, 43(2):91-104.

3. Reeves BC, Quigley M: A review of data-derived methods for assigning causes of death from verbal autopsy data. Int J Epidemiol 1997, 26(5): 1080-9.

4. Ronsmans C, Vanneste AM, Chakraborty J, Van Ginneken J: A comparison of three verbal autopsy methods to ascertain levels and causes of maternal deaths in Matlab, Bangladesh. Int J Epidemiol 1998, 27(4):660-6.

5. Chandramohan D, Maude GH, Rodrigues LC, Hayes RJ: Verbal autopsies for adult deaths: issues in their development and validation. Int J Epidemiol 1994, 23(2):213-22.

6. Quigley MA, Chandramohan D, Setel P, Binka F, Rodrigues LC: Validity of data-derived algorithms for ascertaining causes of adult death in two African sites using verbal autopsy. Trop Med Int Health 2000, 5(I):33-9.

7. Measurement of overall and cause-specific mortality in infants and children: memorandum from a WHO/UNICEF meeting. Bull World Health Organ 1994, 72(5):707-13.

8. Anker M, Black RE, Coldham C, et al: A standard verbal autopsy method for investigating causes of death in infants and children. WHO 1999. unpublished document WHO/CDS/CSR/ISR/ 99.4

9. Kalter HD, Gray RH, Black RE, Gultiano SA: Validation of postmortem interviews to ascertain selected causes of death in children. Int J Epidemiol I990, I 9(2):380-6.

10. Snow RW, Armstrong JR, Forster D, Winstanley MT, Marsh VM, Newton CR, Waruiru C, Mwangi I, Winstanley PA, Marsh K: Childhood deaths in Africa: uses and limitations of verbal autopsies. Lancet 340(88 I 5):35 I-5. 1992 Aug 8
II. Maude GH, Ross DA: The effect of different sensitivity, specificity and cause-specific mortality fractions on the estimation of differences in cause-specific mortality rates in children from studies using verbal autopsies. Int J Epidemiol 1997, 26(5): 1097-106.

12. Quigley MA, Armstrong Schellenberg JR, Snow RW: Algorithms for verbal autopsies: a validation study in Kenyan children. Bull World Health Organ 1996, 74(2): 147-54.

13. Quigley MA, Chandramohan D, Rodrigues LC: Diagnostic accuracy of physician review, expert algorithms and data-derived algorithms in adult verbal autopsies. Int J Epidemiol 1999, 28(6): $108 \mid-7$.

14. Urassa E, Massawe S, Mgaya H, Lindmark G, Nystrom L: Female mortality in reproductive ages in Dar es Salaam, Tanzania. East Afr Med J 1994, 7 I (4):226-3I.

15. Abdulahi $\mathrm{H}$ : Burden of disease in Butajira, southern Ethiopia. Masters Thesis. Addis Ababa University 1998.

16. Shamebo D, Sandstrom A, Muhe L, Freij L, Krantz I, Lonnberg G, Wall $S$ : The Butajira project in Ethiopia: a nested case-referent study of under-five mortality and its public health determinants. Bull World Health Organ 1993, 7 I (3-4):389-96.

17. Transitional Government of Ethiopia. Health Sector Strategy. Addis Ababa 1995.

18. Federal Democratic Republic of Ethiopia: Ministry of Health. Health Information Processing and Documentation Team, Planning and Programming Department. Health and health related indicators. Addis Ababa 1999.

19. Phillips M, Feachem RG, Murray CJ, Over M, Kjellstrom T: Adult health: a legitimate concern for developing countries. $\mathrm{Am} J$ Public Health 1993, 83(I I): 1527-30.

20. Bang AT, Bang RA: Diagnosis of causes of childhood deaths in developing countries by verbal autopsy: suggested criteria. The SEARCH Team. Bull World Health Organ 1992, 70(4):499-507.

21. Kaufman JS, Asuzu MC, Rotimi CN, Johnson OO, Owoaje EE, Cooper RS: The absence of adult mortality data for sub-Saharan Africa: a practical solution. Bull World Health Organ 1997, 75(5):389-95.

22. Berhane $Y$, Wall $S$, Kebede D, Emmelin A, Enquselassie $F$, Byass $P$, Muhe L, Anderssson T, Deyessa N, Gossaye Y, Hogberg U, Alem A, Dahlblom K: Establishing an epidemiological laboratory in rural areas- potentials for public health research and interventions: the Butajira Rural Health Programme 1987-99. Ethiop J Health Dev 1999, 13(special issue): I-47.

23. Federal Democratic Republic of Ethiopia: Ministry of Health. Health Information Processing and Documentation Team, Planning and Programming Department. Health and health related indicators. Addis Ababa 2000.

24. Baqui AH, Black RE, Arifeen SE, Hill K, Mitra SN, al Sabir A: Causes of childhood deaths in Bangladesh: results of a nationwide verbal autopsy study. Bull World Health Organ 1998, 76(2):|6I-7|.

25. Oxaal Z, Baden S: Challenges to women's reproductive health: Maternal mortality. BRIDGE briefings on development and gender 1996. Report No: 38

26. Abou Zahr C, Royston E, eds: Maternal Mortality: A Global Fact book. World Health Organization, Geneva I991.

27. Graham W, Airey P: Measuring maternal mortality: sense and sensitivity. Health Policy and Planning 1987, 2(4):323-333.

28. Byass $\mathrm{P}$, Huong $\mathrm{D}$, Minh $\mathrm{H}$ : A probabilistic approach to interpreting verbal autopsies: methodology and preliminary validation in Vietnam. Scand J Public Health 2003, 3 I (Suppl 62):32-37.

29. Berhane $Y$, Hogberg U, Byass P, Wall S: Gender, literacy, and survival among Ethiopian adults, 1987-96. Bull World Health Organ 2002, 80(9):714-720.

\section{Pre-publication history}

The pre-publication history for this paper can be accessed here:

http://www.biomedcentral.com/1471-2458/5/58/prepub 